\title{
Numerical Simulation Characteristics of Logging Response in Water Injection Well by Reproducing Kernel Method
}

\author{
Ming-Jing Du, ${ }^{1}$ Yu-Lan Wang, ${ }^{1}$ and Temuer Chaolu ${ }^{1,2}$ \\ ${ }^{1}$ Department of Mathematics, Inner Mongolia University of Technology, Hohhot 010051, China \\ ${ }^{2}$ Department of Mathematics, Shanghai Maritime University, Shanghai 201306, China \\ Correspondence should be addressed to Yu-Lan Wang; wylnei@163.com
}

Received 15 April 2015; Revised 7 November 2015; Accepted 11 November 2015

Academic Editor: Naohisa Otsuka

Copyright (c) 2015 Ming-Jing Du et al. This is an open access article distributed under the Creative Commons Attribution License, which permits unrestricted use, distribution, and reproduction in any medium, provided the original work is properly cited.

\begin{abstract}
Reproducing kernel Hilbert space method (RKHSM) is an effective method. This paper, for the first time, uses the traditional RKHSM for solving the temperature field in two phase flows of multilayer water injection well. According to $2 \mathrm{D}$ oil-water temperature field mathematical model of two phase flows in cylindrical coordinates, selecting the properly initial and boundary conditions, by the process of Gram-Schmidt orthogonalization, the analytical solution was given by reproducing kernel functions in a series expansion form, and the approximate solution was expressed by $n$-term summation. The satisfied numerical results were carried out by Mathematica 7.0, showing that the larger the difference between injected water temperature and initial borehole temperature or water injection conditions, the more obvious the indication of water accepting zones. The numerical examples evidence the feasibility and effectiveness of the proposed method of the two phase flows in engineering.
\end{abstract}

\section{Introduction}

As we known, during the middle and late stage of water flooding oil field it is difficult for temperature log to reflect actual water injection profile in normal water injection conditions; at the same time, with the deepening of oil field development and the extension of exploitation time, a phenomenon of the viscosity of oil in the well became stickier and the production is reduced, leading to a large amount of stored oil in underground which can not be mined. Gradually people found that water injection can save this problem. By injecting water, it can keep formation energy, enhance crude oil recovery ratio, and insure long-term high and stable production; at the same time, pressure in oil layer is improved, which can guarantee the high oil field production.

In recent years, many researchers in order to improve temperature $\log$ to determine water injection profile, lots of mathematical methods were applied in temperature log such as the ADI method [1], the full implicit form of finite difference method [2], the finite difference method [3], the implicit finite difference method [4], the alternating direction implicit method (ADI), and speedup method [5].

In this paper, RKHSM method is used to simulate the temperature model. It is well known that RKHSM is a simple and accurate method. In recent years, there has been a growing interest in using RKHSM to solve mathematical problems [6-14], but there is no one applying this method into characteristics of logging response in two phase flows problems. This paper tries to study the temperature field in water injection with RKHSM. By analyzing the simulated results we can conclude that temperature logging can distinguish water entry zones from non-water entry zones through hot-water injection for short periods of time, enlarging water injection velocity, selecting reasonable shut-in time. It is economical and reasonable way to use short, fast, hot-water injection in order to change the condition that temperature $\log$ can not delineate water injection profile.

\section{Mathematical Modeling}

2.1. The Mathematical Model. In water injection well, the temperature field model is [5]

$$
\begin{gathered}
\frac{\partial^{2}\left(\lambda_{w} T\right)}{\partial z^{2}}+\frac{\partial^{2}\left(\lambda_{w} T\right)}{\partial r^{2}}+\frac{1}{r} \frac{\partial\left(\lambda_{w} T\right)}{\partial r} \\
=\frac{\partial\left(c_{w} \rho_{w} T\right)}{\partial t}+\frac{\partial\left(c_{w} \rho_{w} \nu_{z} T\right)}{\partial z} .
\end{gathered}
$$


$T$ is the temperature, $\lambda_{w}$ is the thermal conductivity of water, and $F_{w}$ is water saturation. $z$ is the depth of the oil wellbore, and $r$ is the radial distance. $\rho_{w}$ is the density of water, and $c_{w}$ are the specific heat of water. $v_{z}$ is the velocity of fluid inside the oil wellbore. The initial temperature of the formation and wellbore is at the geothermal condition which can be written as $\left.T\right|_{t=0}=T_{0}=a+b z ; a$ is the formation temperature when $z=0, b$ is the geothermal gradient, the boundary of adiabatic condition is $\left.\left(\partial\left(\lambda_{w} T\right) / \partial r\right)\right|_{r=0}=0$, the upper boundary of adiabatic condition is $\left.\left(\partial\left(\lambda_{w} T\right) / \partial z\right)\right|_{z=H}=0$, and the under boundary of adiabatic condition is $\left.\left(\partial\left(\lambda_{w} T\right) / \partial z\right)\right|_{z=0}=0$.

In order to solve (1), we introduce the reproducing kernel spaces.

2.2. Reproducing Kernel Hilbert Spaces Method (RKHSM). There are several reproducing kernel spaces (RKHS) to introduce: $W_{2}^{1}[0,1], W_{2}^{3}[0,1], W_{2.1}^{3}[0,1], W_{2}^{3}[0,1] \otimes W_{2.1}^{3}[0,1]$, and $W_{2}^{1}[0,1] \otimes W_{2}^{1}[0,1]$.

(1) Space $W_{2}^{1}[0,1]=\{u \mid u$ is one-variable absolutely continuous function, $\left.u^{\prime} \in L^{2}[0,1]\right\}$.

An inner product is

$$
\begin{array}{r}
\langle u(x), v(x)\rangle_{W_{2}^{1}}=u(0) v(0)+\int_{0}^{1} u^{\prime}(x) \cdot v^{\prime}(x) d x, \\
u(x), v(x) \in W_{2}^{1}[0,1] .
\end{array}
$$

The reproducing kernel is

$$
R_{x}^{\{1\}}(y)= \begin{cases}1+y, & x>y \\ 1+x, & y>x .\end{cases}
$$

(2) Space $W_{2}^{3}[0,1]=\left\{u \mid u, u^{\prime}, u^{\prime \prime}\right.$ are one-variable absolutely continuous functions, $u(0)=u^{\prime}(0)=0, u^{\prime \prime \prime} \epsilon$ $\left.L^{2}[0,1]\right\}$.

An inner product is

$$
\begin{aligned}
\langle u(x), v(x)\rangle_{W_{2}^{3}}= & \sum_{i=1}^{2} u^{(i)}(0) v^{(i)}(0) \\
& +\int_{0}^{1} u^{\prime \prime \prime}(x) \cdot v^{\prime \prime \prime}(x) d x, \\
& u(x), v(x) \in W_{2}^{3}[0,1] .
\end{aligned}
$$

The reproducing kernel is

$$
\begin{aligned}
& R_{x}^{\{3\}}(y) \\
& = \begin{cases}\frac{y^{2}\left(-5 x y^{2}+y^{3}+10 x^{2}(3+y)\right)}{120}, & x>y, \\
\frac{x^{2}\left(x^{3}-5 x^{2} y+30 y^{2}+10 x y^{2}\right)}{120}, & y>x .\end{cases}
\end{aligned}
$$

(3) Space $W_{2.1}^{3}[0,1]=\left\{u \mid u, u^{\prime}, u^{\prime \prime}\right.$ are one-variable absolutely continuous functions, $u^{\prime}(0)=u^{\prime}(1)=0, u^{\prime \prime \prime} \epsilon$ $\left.L^{2}[0,1]\right\}$.

An inner product is

$$
\begin{aligned}
\langle u(x), v(x)\rangle_{W_{2.1}^{3}}= & \sum_{i=1}^{2} u^{(i)}(0) v^{(i)}(0) \\
& +\int_{0}^{1} u^{\prime \prime \prime}(x) \cdot v^{\prime \prime \prime}(x) d x, \\
& \quad u(x), v(x) \in W_{2.1}^{3}[0,1] .
\end{aligned}
$$

The reproducing kernel is

$$
R_{x}^{\{3\}}(y)= \begin{cases}-\frac{\left(1-4 x+18 x^{2}\right)\left(1-4 y+18 y^{2}\right)}{768}+\frac{\left(120-5 x y^{4}+y^{5}+10 x^{2} y^{2}(3+y)\right)}{120}, & x>y \\ -\frac{\left(1-4 x+18 x^{2}\right)\left(1-4 y+18 y^{2}\right)}{768}+\frac{\left(120+x^{5}-5 x^{4} y+30 x^{2} y^{2}+10 x^{3} y^{2}\right)}{120}, & y>x\end{cases}
$$

(4) The reproducing kernel space is

$$
\begin{aligned}
W & =W_{2}^{3}[0,1] \otimes W_{2.1}^{3}[0,1]=\left\{u(x, y) \mid \frac{\partial^{n+m}}{\partial x^{n} \partial y^{m}}\right. \\
& \cdot u(x, y)
\end{aligned}
$$

are two-variable complete continuous functions, $n$

$$
=0,1,2, m=0,1,2, \frac{\partial^{p+q}}{\partial x^{p} \partial y^{q}} u(x, y) \in L^{2}(D), \quad p
$$

$$
=0,1,2, q=0,1,2, u(x, 0)=u^{\prime}(x, 0)=u(0, y)
$$$$
\left.=u^{\prime}(1, y)=0\right\}=\{u(x, y) \mid
$$$$
\left.\sum_{i=1}^{\infty} \sum_{j=1}^{\infty} c_{i j} \widetilde{v}_{1}^{(i)}(x) \cdot v_{2}^{(j)}(y): \forall \sum_{i=1}^{\infty} \sum_{j=1}^{\infty}\left|c_{i j}\right|^{2}<\infty\right\},
$$ 
where $D=[0,1] \times[0,1]$ and $\widetilde{v}_{k}^{(i)}(k=1,2)$ is a complete orthogonal function system of $W_{2}^{3}[0,1]$ and $W_{2.1}^{3}[0,1]$.

For any $u(x, y)=\sum_{i=1}^{\infty} \sum_{j=1}^{\infty} c_{i j} \widetilde{v}_{1}^{(i)}(x) \cdot v_{2}^{(j)}(y) \in W$, $v(x, y)=\sum_{i=1}^{\infty} \sum_{j=1}^{\infty} d_{k l} \widetilde{v}_{1}^{(k)}(x) \cdot v_{2}^{(l)}(y) \in W$. An inner product $\langle u, v\rangle=\sum_{i=1}^{\infty} \sum_{j=1}^{\infty} \sum_{i=1}^{\infty} \sum_{j=1}^{\infty} c_{i j} \bar{d}_{k l}\left\langle\widehat{v}_{1}^{(i)}, \widetilde{v}_{1}^{(k)}\right\rangle_{1}\left\langle v_{2}^{(j)}, v_{2}^{(l)}\right\rangle_{2}=$ $\sum_{i=1}^{\infty} \sum_{j=1}^{\infty} c_{i j} \bar{d}_{i j}$, so the reproducing kernel of $W$ is $R_{(\xi, \eta)}^{\{3\}}(x, y)=R_{\xi}^{\{3\}}(x) \times R_{\eta}^{\{3\}}(y)$; by the same way, we continue to get $W_{1}=W_{2}^{1}[0,1] \otimes W_{2}^{1}[0,1]$, and the reproducing kernel of $W_{1}$ is $R_{(\xi, \eta)}^{\{1\}}(x, y)=R_{\xi}^{\{1\}}(x) \times R_{\eta}^{\{1\}}(y)$.

2.3. Analytical Solution and Approximate Solution. On defining the linear operator $L, L^{-1}$ is existent: $W(D) \rightarrow W_{1}(D)$ as [7]

$$
\begin{gathered}
(L T)(r, z)=\frac{\partial^{2}\left(\lambda_{l} T\right)}{\partial z^{2}}+\frac{\partial^{2}\left(\lambda_{l} T\right)}{\partial r^{2}}+\frac{1}{r} \frac{\partial\left(\lambda_{l} T\right)}{\partial r}, \\
F(r, z)=\frac{\partial\left(c_{l} \rho_{l} T\right)}{\partial t}-\frac{\partial\left(c_{l} \rho_{l} \nu_{z} T\right)}{\partial z},
\end{gathered}
$$

and model problem (1) changes to the following problem:

$$
(L T)(r, z, t)=F(r, z, t) .
$$

$W(D)$ is a RKHS with the reproducing kernel $R_{(\xi, \eta)}^{\{3\}}(r, z)$, $W_{1}(D)$ is a RKHS with the reproducing kernel $R_{(\xi, \eta)}^{\{,\}}(r, z)$. According to [11], it can be noted that $\phi_{i}(r, z)=R_{\left(r_{i}, z_{i}\right)}^{\{r, z)}(r, z)$ and $\psi_{i}(r, z)=L^{*} \phi_{i}(r, z)$, where $L^{*}$ is the adjoint operator of $L$. The orthonormal system $\left\{\bar{\psi}_{i}(r, z)\right\}_{i=1}^{\infty}$ of $W(D)$ can be derived from the process of Gram-Schmidt orthogonalization of $\left\{\psi_{i}(r, z)\right\}_{i=1}^{\infty}$ as $\bar{\psi}_{i}(r, z)=\sum_{k=1}^{i} \beta_{i k} \psi_{k}(r, z)$. If $\left\{\left(r_{i}, z_{i}\right)\right\}_{i=1}^{\infty}$ is dense in $W(D)$ and $\beta_{i k}$ is the coefficient of orthogonalization, then $T(r, z, t)=\sum_{i=1}^{\infty} \sum_{k=1}^{i} \beta_{i k} F\left(r_{k}, z_{k}, t\right) \bar{\psi}_{i}(r, z)$ is an analytical solution of (10). The approximate solution is $T_{n}(r, z, t)=$ $\sum_{i=1}^{n} \sum_{k=1}^{i} \beta_{i k} F\left(r_{k}, z_{k}, t\right) \bar{\psi}_{i}(r, z), i=1, \ldots, n$. If (10) is nonlinear, the approximate solution to (10) can be expressed by $T_{n}(r, z, t)=\sum_{i=1}^{n} \sum_{k=1}^{i} \beta_{i k} F\left(r_{k}, z_{k}, T_{k-1}\left(r_{k}, z_{k}\right), t\right) \bar{\psi}_{i}(r, z), i=$ $1, \ldots, n$.

The convergence analysis, error analysis, and stability have been done by many researchers [6-14], and this paper no longer discusses them.

2.4. Numerical Experiment. In order to show RKHSM is effective, a nonlinear equation is used as a test to prove the high accuracy of the method. Select the above conditions and boundary conditions and let $\lambda_{l}=1$ and $D=(0,1) \times(0,1)$; the equation has an exact solution of the form $T(r, z, t)=e^{-t}$. $\sin 10 r \cdot \cos 10 z$. By Mathematica 7.0, using our method, we choose the number of nodes as 23 and obtain the approximate solution $T_{23}$; the comparison of the results with the exact solution is shown in Table 1, and they are found to be in good agreement with each other. Figure 1 is the exact solution $T(r, z, 1)$, and Figure 2 is the error $\left(T-T_{23}\right)$.
TABLE 1: Numerical results at $t=1$.

\begin{tabular}{lccc}
\hline$(r, z)$ & $\begin{array}{c}\text { Approximate } \\
\text { solution }\end{array}$ & $\begin{array}{c}\text { Exact } \\
\text { solution }\end{array}$ & Absolute error \\
\hline$(0.1,0.1)$ & 0.165583 & 0.167256 & 0.001673 \\
$(0.2,0.2)$ & -0.373791 & -0.373791 & 0.001392 \\
$(0.3,0.3)$ & -0.050882 & -0.051396 & 0.000514 \\
$(0.4,0.4)$ & 0.180162 & 0.181982 & 0.001820 \\
$(0.5,0.5)$ & -0.099066 & -0.100067 & 0.001001 \\
$(0.6,0.6)$ & -0.097710 & -0.098697 & 0.000987 \\
$(0.7,0.7)$ & 0.180390 & 0.182212 & 0.001822 \\
$(0.8,0.8)$ & -0.052427 & -0.052957 & 0.000530 \\
$(0.9,0.9)$ & -0.136755 & -0.138136 & 0.001381 \\
$(1.0,1.0)$ & 0.166248 & 0.167927 & 0.001679 \\
\hline
\end{tabular}

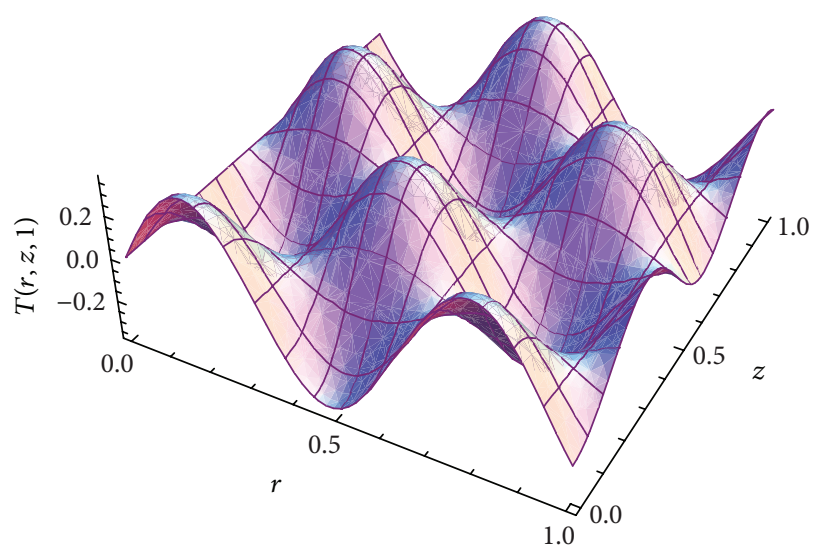

FIgURE 1: Exact solution $T(r, z, 1)$.

\section{Numerical Simulation Results and Discussion}

Using the common body structure of vertical wells [5], assuming that the fluid is Newton fluid, the radius of oil well is $0.1 \mathrm{~m}$, and the geothermal gradient is $0.025^{\circ} \mathrm{C} / \mathrm{m}$; ignoring the influence of casing and cement, the initial formation temperature is $15^{\circ} \mathrm{C}$. The interlayer between the two injections is $20 \mathrm{~m}$. The thermal conductivity of water and oil is $4182 \mathrm{~J} / \mathrm{kg} \cdot \mathrm{K}$ and $2234.2 \mathrm{~J} / \mathrm{kg} \cdot \mathrm{K}$, the density of water and oil is $1000 \mathrm{~kg} / \mathrm{m}^{3}$ and $800 \mathrm{~kg} / \mathrm{m}^{3}$, and the specific heat of water and oil is $0.618 \mathrm{~W} / \mathrm{m} \cdot \mathrm{K}$ and $0.156 \mathrm{~W} / \mathrm{m} \cdot \mathrm{K}$. The boundary of adiabatic condition is $\left.T\right|_{z=0}=15^{\circ} \mathrm{C}$, $\left.\left(\partial\left(\lambda_{w} T\right) / \partial r\right)\right|_{r=0}=0$, the upper boundary of adiabatic condition is $\left.\left(\partial\left(\lambda_{w} T\right) / \partial z\right)\right|_{z=1}=0$, and the under boundary of adiabatic condition is $\left.\left(\partial\left(\lambda_{w} T\right) / \partial z\right)\right|_{z=0}=0$.

3.1. Effect of Different Injection Rate. The injection temperature is $80^{\circ} \mathrm{C}$; temperatures of numerical simulations are given in Figure 1 at $t=1 \mathrm{~h}$ when the injection rate is $0.0059 \mathrm{~m} / \mathrm{s}$, $0.095 \mathrm{~m} / \mathrm{s}$, and $0.0368 \mathrm{~m} / \mathrm{s}$.

From Figure 3, it can be seen that the temperature of injection layer is more changed than others when $v_{z}=$ $0.0059 \mathrm{~m} / \mathrm{s}$. The temperature in injection layer is obviously changed when the injection rate is small, because the fluid 


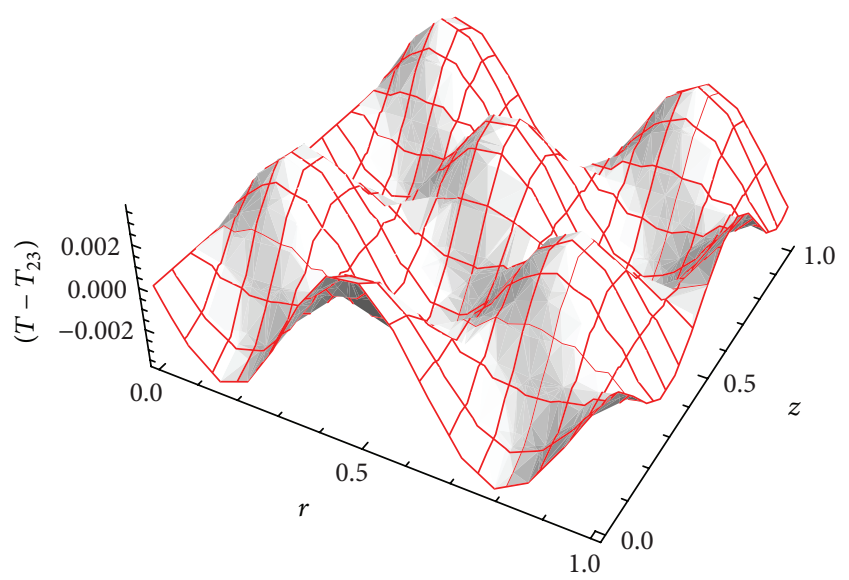

Figure 2: Errors $\left(T-T_{23}\right)$.

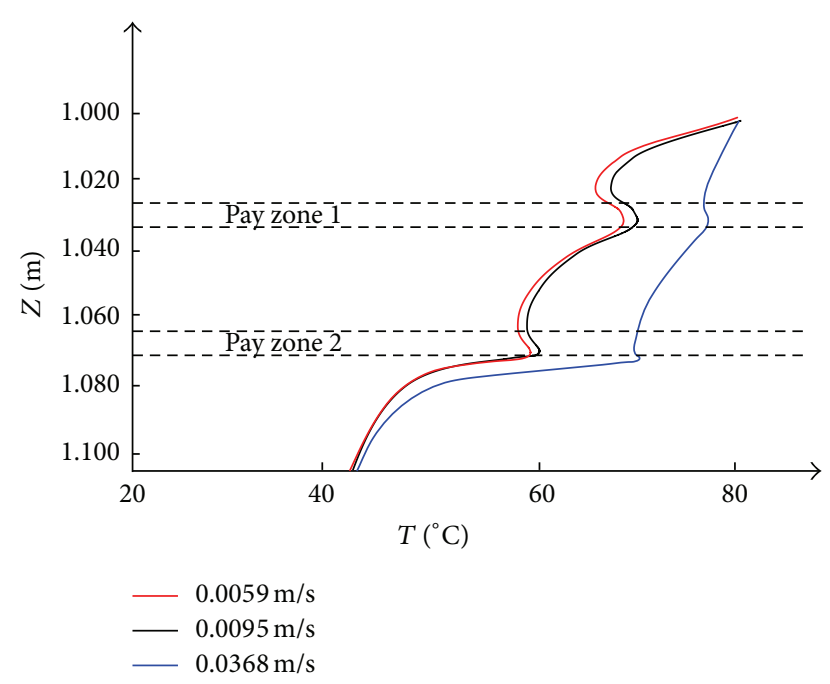

Figure 3: Effect of different injection rates $0.0059 \mathrm{~m} / \mathrm{s}, 0.095 \mathrm{~m} / \mathrm{s}$, and $0.0368 \mathrm{~m} / \mathrm{s}$.

and borehole wall exchange the heat transfer sufficiently in the wellbore.

3.2. Effect of Different Injection Temperature. When injection rate $v_{z}=0.0059 \mathrm{~m} / \mathrm{s}$, the temperature of numerical simulation when injection temperature is $20^{\circ} \mathrm{C}, 60^{\circ} \mathrm{C}$, and $80^{\circ} \mathrm{C}$ is given in Figure 4 at $t=1 \mathrm{~h}$.

Figure 4 shows the temperature profile is less obvious when the injection temperature is close to the original formation temperature $\left(42.5^{\circ} \mathrm{C}\right)$, and the temperature profile is more obviously changed when the injection temperature is further deviated from the original formation temperature $\left(20^{\circ} \mathrm{C}, 80^{\circ} \mathrm{C}\right)$.

3.3. Effect of Different Injection Time. When injection rate $v_{z}=0.0059 \mathrm{~m} / \mathrm{s}$, the injection temperature is $80^{\circ} \mathrm{C}$, and the temperature of numerical simulation when injection time is $0.1 \mathrm{~d}, 10 \mathrm{~d}$, and $100 \mathrm{~d}$ is given in Figure 5.

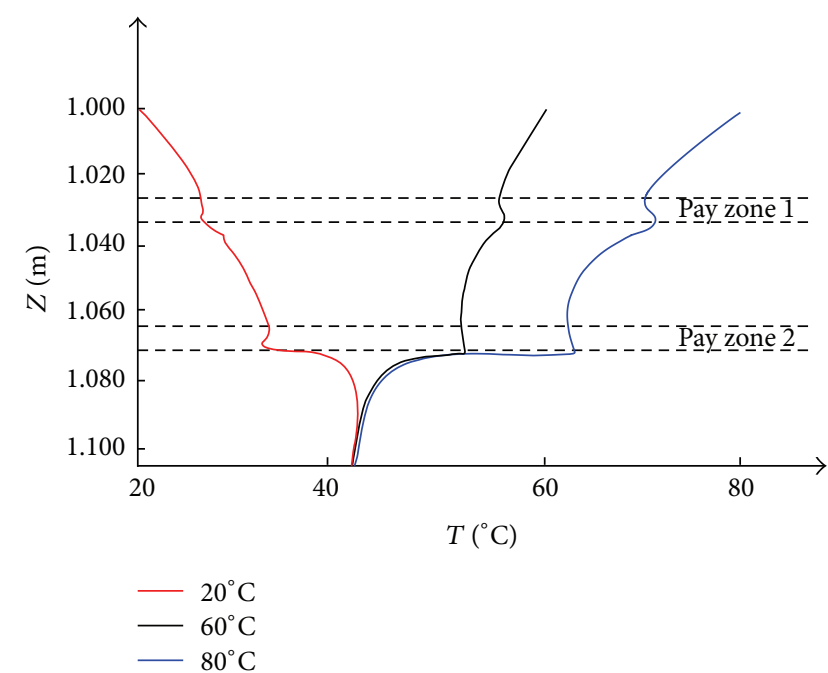

Figure 4: Effect of different injection temperatures $20^{\circ} \mathrm{C}, 60^{\circ} \mathrm{C}$, and $80^{\circ} \mathrm{C}$.

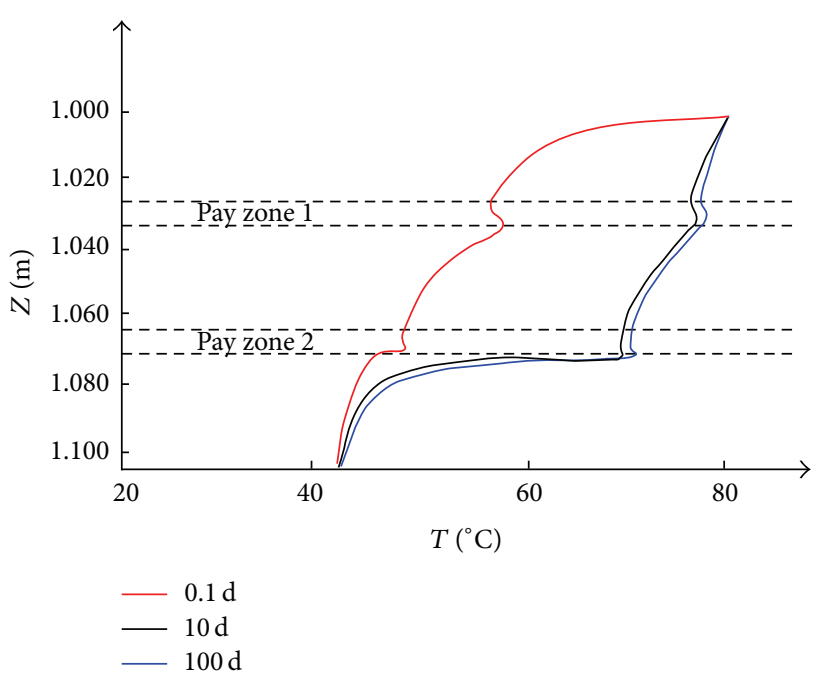

Figure 5: Effect of different injection times $0.1 \mathrm{~d}, 10 \mathrm{~d}$, and $100 \mathrm{~d}$.

Figure 5 presents that the temperature of injection layer is less changed compared with others when $t=0.1 \mathrm{~d}$; this is because the fluid and borehole wall do not exchange the heat transfer sufficiently. As the temperature of fluid and borehole wall becomes consistent when injection time is long, temperature profile can not be distinguished. Therefore, reasonable injection time is good for temperature field of the recovery.

3.4. Effect of Different Oil Layer Thickness. When injection rate $v_{z}=0.0059 \mathrm{~m} / \mathrm{s}$, the injection temperature is $80^{\circ} \mathrm{C}$, and injection time is $t=1 \mathrm{~h}$; the temperature of numerical simulation when oil layer thickness is $1 \mathrm{~m}, 6 \mathrm{~m}$, and $10 \mathrm{~m}$ is given in Figure 6.

In Figure 6, when oil layer thickness is $1 \mathrm{~m}$, the temperature of injection layer is less changed compared with others. When the oil layer is thick, the temperature is high, because 


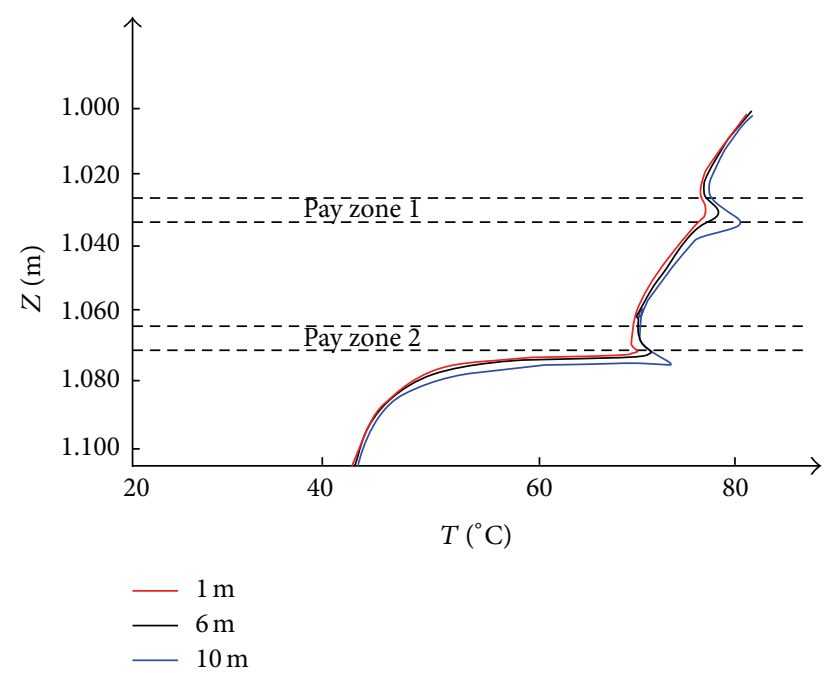

FIGURE 6: Effect of different oil layer thicknesses $1 \mathrm{~m}, 6 \mathrm{~m}$, and $10 \mathrm{~m}$.

the fluids are fully blended in the entrance of the injection layer.

\section{Conclusions}

In this paper, RKHSM is used to solve a class of linear or nonlinear partial differential equations which can describe the temperature field in water injection well; it can be seen that the method is feasible. According to the numerical simulation results in Section 3, the following conclusions are given.

During the water injection wellbore production, different injection-production conditions make different temperature profile. By analyzing the simulated results we can conclude that temperature logging can distinguish water entry zones from non-water entry zones through hot-water injection for short periods of time, enlarging water injection velocity, selecting reasonable shut-in time, so we can use the short, fast, hot-water injection in order to change the condition that temperature $\log$ can not delineate water injection profile.

\section{Conflict of Interests}

The authors declare that there is no conflict of interests regarding the publication of this paper.

\section{Acknowledgments}

This paper is supported by the Natural Science Foundation of China (no. 11361037), the Natural Science Foundation of Inner Mongolia (no. 2013MS0109, no. 2015MS0118), Project Application Technology Research and Development Foundation of Inner Mongolia (no. 20120312), and Autonomous Region Ph.D. Research Innovation Project of Inner Mongolia (no. B20141012808).

\section{References}

[1] Y. Shi, Y. Song, and H. Liu, "Numerical simulation of downhole temperature distribution in producing oil wells," Applied Geophysics, vol. 5, no. 4, pp. 340-349, 2008.

[2] M. Ren and H. L. Ma, "Simulation of the characteristics of logging response in temperature field in wellbore," Chinese Journal of Engineering Geophysics, vol. 11, no. 1, pp. 71-76, 2014.

[3] S. G. Li and X. P. Li, "Injection well shaft two-dimensional numerical simulation of the transient temperature field," OilGasfield Surface Engineering, vol. 30, no. 1, pp. 42-43, 2011.

[4] M. Yang, Y.-F. Meng, G. Li, J.-M. Deng, L. Zhang, and S.H. Tang, "Effects of the radial temperature gradient and axial conduction of drilling fluid on the wellbore temperature distribution," Acta Physica Sinica, vol. 62, no. 7, Article ID 079101, 9 pages, 2013.

[5] Z. S. Xiao and Y. J. Song, "Temperature field model and numerical simulation of multilayer water injection well," Progress in Geophysics, vol. 20, no. 3, pp. 801-807, 2005.

[6] Y. L. Wang, L. J. Su, X. Cao, and X. Li, "Using reproducing kernel for solving a class of singularly perturbed problems," Computers \& Mathematics with Applications, vol. 61, no. 2, pp. 421-430, 2011.

[7] M. Mohammadi and R. Mokhtari, "Solving the generalized regularized long wave equation on the basis of a reproducing kernel space," Journal of Computational and Applied Mathematics, vol. 235, no. 14, pp. 4003-4014, 2011.

[8] J. Du and M. G. Cui, "Solving the semilinear heat equation with integral boundary conditions in the reproducing kernel space," Acta Mathematica Scientia, vol. 30, no. 1, pp. 245-257, 2010.

[9] F. Geng, M. Cui, and B. Zhang, "Method for solving nonlinear initial value problems by combining homotopy perturbation and reproducing kernel Hilbert space methods," Nonlinear Analysis. Real World Applications, vol. 11, no. 2, pp. 637-644, 2010.

[10] C.-L. Li and M.-G. Cui, "The exact solution for solving a class nonlinear operator equations in the reproducing kernel space," Applied Mathematics and Computation, vol. 143, no. 2-3, pp. 393-399, 2003.

[11] S.-S. Xie, S. Heo, S. Kim, G. Woo, and S. Yi, "Numerical solution of one-dimensional Burgers' equation using reproducing kernel function," Journal of Computational and Applied Mathematics, vol. 214, no. 2, pp. 417-434, 2008.

[12] H. Du and M. Cui, "Approximate solution of the Fredholm integral equation of the first kind in a reproducing kernel Hilbert space," Applied Mathematics Letters, vol. 21, no. 6, pp. 617-623, 2008.

[13] Z. Chen and Y. Zhou, "An efficient algorithm for solving Hilbert type singular integral equations of the second kind," Computers \& Mathematics with Applications, vol. 58, no. 4, pp. 632-640, 2009.

[14] L. Mu and H. Du, "The solution of a parabolic differential equation with non-local boundary conditions in the reproducing kernel space," Applied Mathematics and Computation, vol. 202, no. 2, pp. 708-714, 2008. 


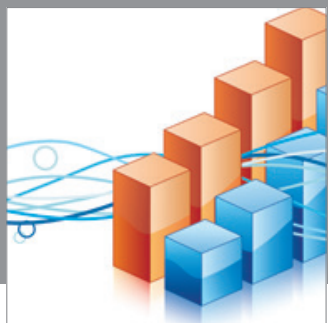

Advances in

Operations Research

mansans

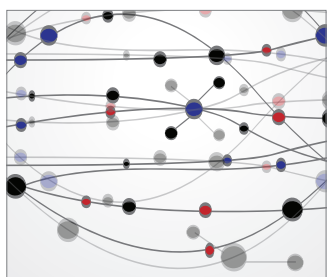

The Scientific World Journal
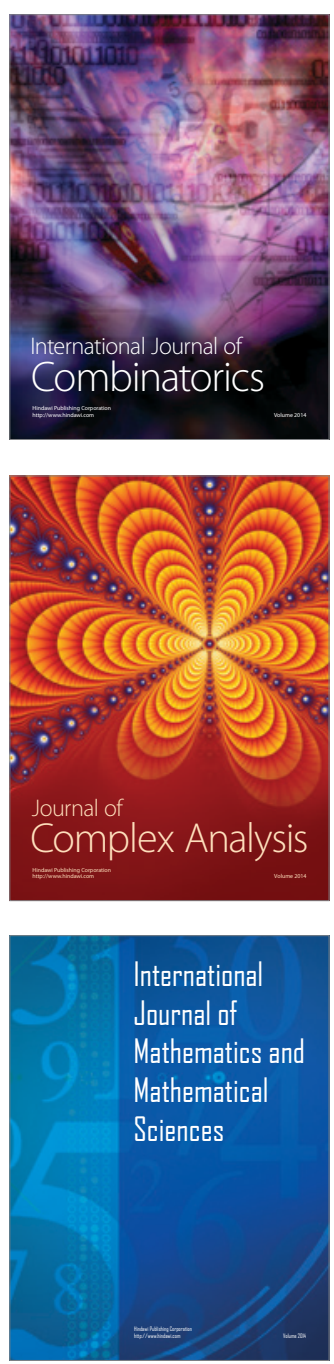
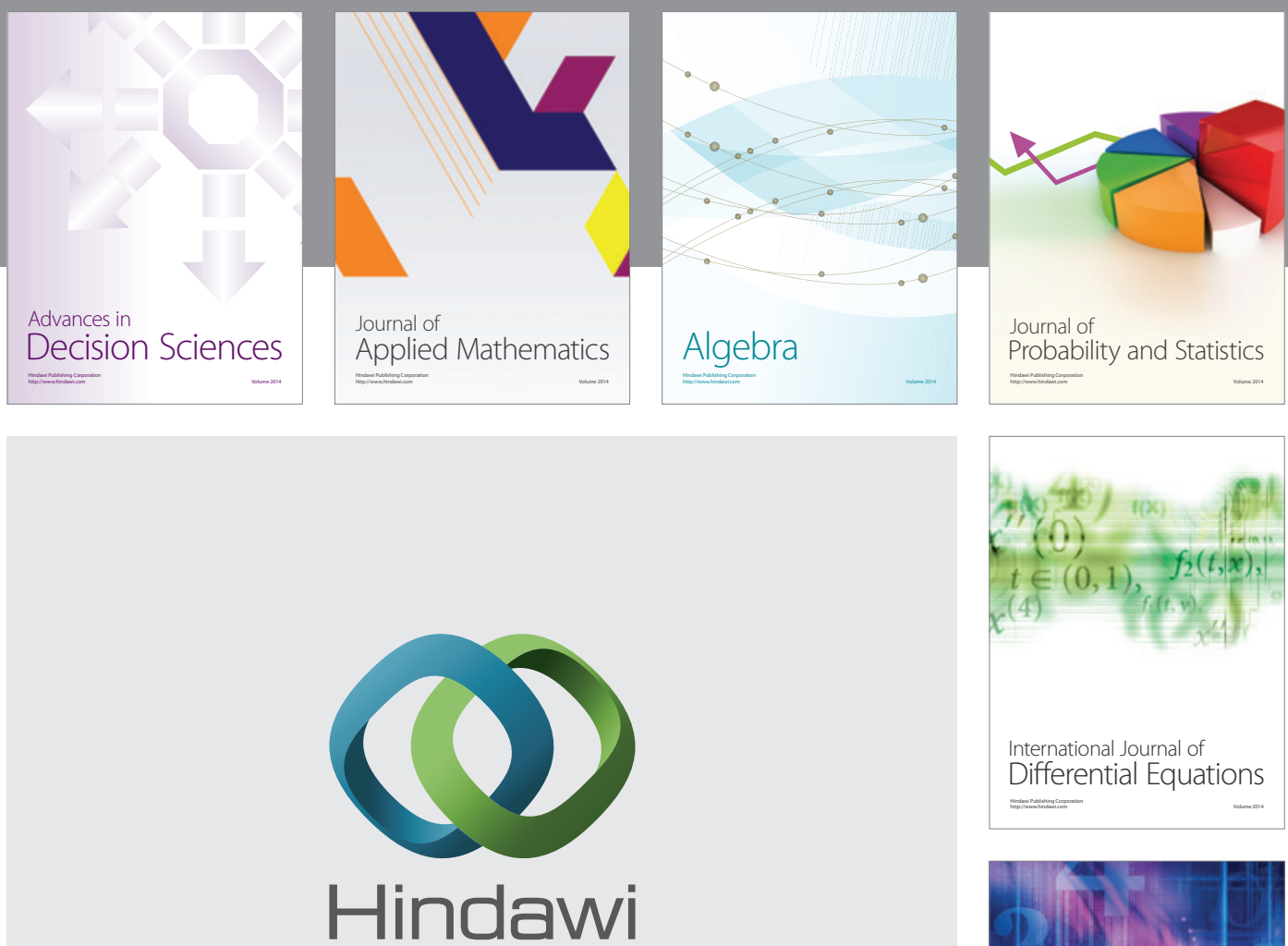

Submit your manuscripts at http://www.hindawi.com
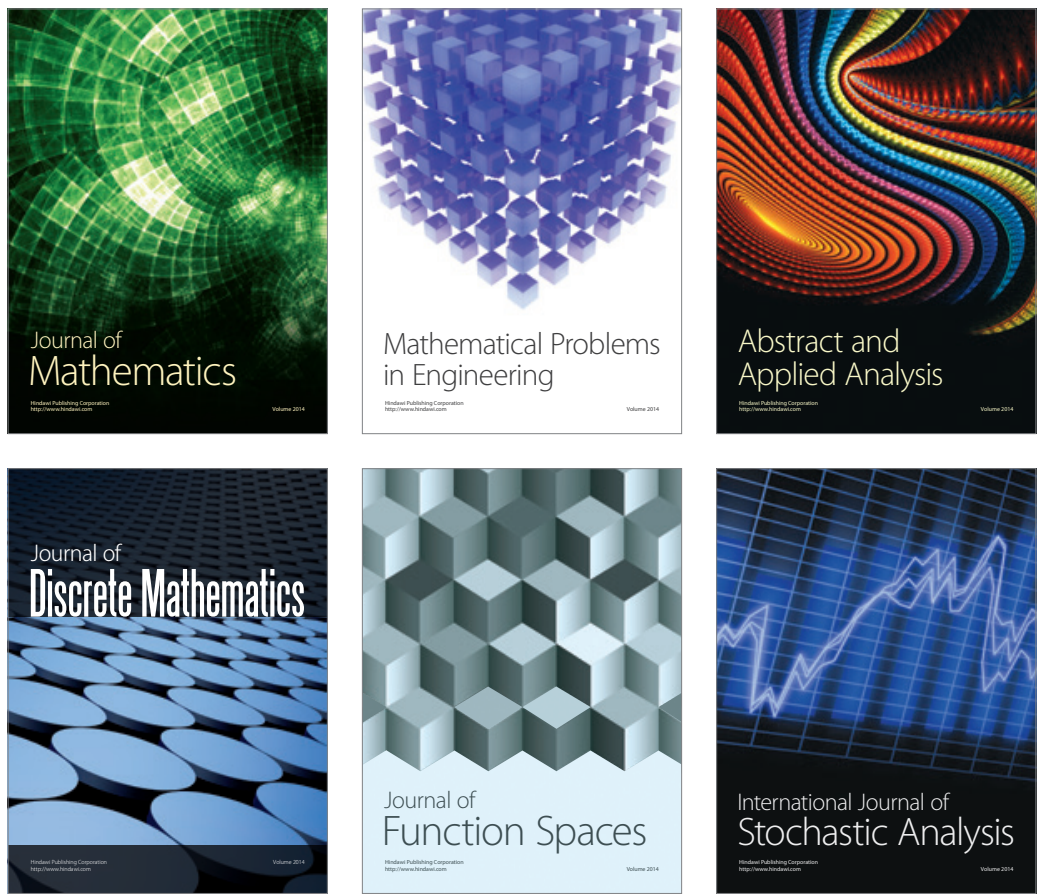

Journal of

Function Spaces

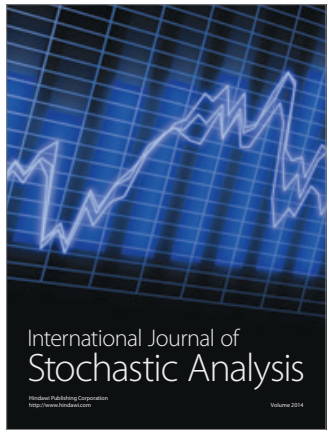

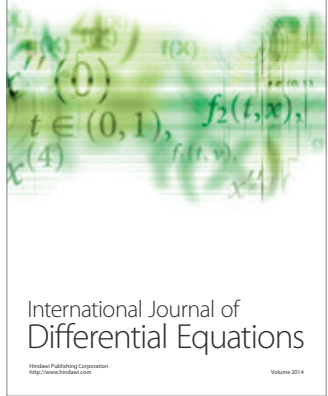
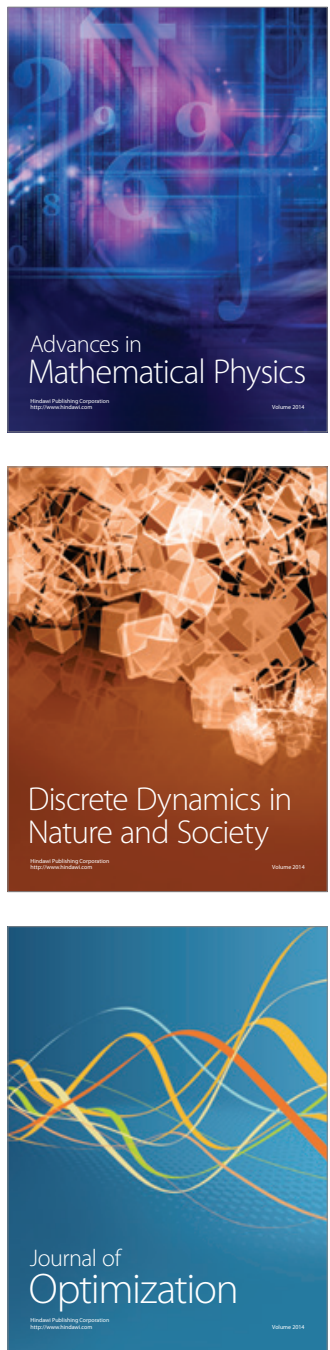